\title{
Annales historiques de ta Annales historiques de la Révolution
}

française française

367 | janvier-mars 2012

Théâtre et révolutions

\section{Michaël culOMA, La religion civile de Rousseau à Robespierre}

\section{Caroline Chopelin-Blanc}

\section{(2) OpenEdition}

\section{Journals}

\section{Édition électronique}

URL : https://journals.openedition.org/ahrf/12385

DOI : $10.4000 /$ ahrf.12385

ISSN : 1952-403X

Éditeur :

Armand Colin, Société des études robespierristes

Édition imprimée

Date de publication : 1 mars 2012

Pagination : 226-228

ISSN : 0003-4436

Référence électronique

Caroline Chopelin-Blanc, « Michaël cutoma, La religion civile de Rousseau à Robespierre », Annales

historiques de la Révolution française [En ligne], 367 | janvier-mars 2012, mis en ligne le 12 septembre

2012, consulté le 01 juillet 2021. URL : http://journals.openedition.org/ahrf/12385 ; DOI : https:// doi.org/10.4000/ahrf.12385

Ce document a été généré automatiquement le 1 juillet 2021.

Tous droits réservés 


\title{
Michaël CULOMA, La religion civile de Rousseau à Robespierre
}

\author{
Caroline Chopelin-Blanc
}

\section{RÉFÉRENCE}

Michaël culoma, La religion civile de Rousseau à Robespierre, Paris, L'Harmattan, collection Historiques, 2010, 278 p., ISBN 978-2-296-10917-9, $27 €$.

1 Cet ouvrage est la version publiée d'une thèse d'histoire du droit soutenue en 2008 à Aix-Marseille (dir. C. Bruschi) sous le titre L'idée de religion civile dans le débat politique de la parution du Contrat social au 9 thermidor An II. L'auteur y analyse la réception du concept rousseauiste de "religion civile », de 1762, année de parution du Contrat social, au 18 floréal an II (7 mai 1794), date de la reconnaissance de «l'existence de l'Être suprême » par la Convention. Dans le huitième chapitre du livre IV du Contrat social, Rousseau propose, en la théorie de la religion civile, une conceptualisation novatrice du rapport politico-religieux, dont la finalité est de former des citoyens attachés à leur patrie. La réception de cette théorie rousseauiste dans le débat politique oscille entre le

rejet, le dénigrement, l'instrumentalisation, l'adhésion, sous-tendue par une compréhension plus ou moins claire du concept. Pour étudier les modalités de cette réception, l'auteur s'appuie sur quelques auteurs chrétiens des années 1760-1780, pour l'essentiel des prédicateurs et des apologistes célèbres en leur temps, comme JeanBaptiste Massillon et Nicolas-Sylvestre Bergier. Pour la période révolutionnaire, les débats reproduits dans les Archives parlementaires constituent sa documentation principale. Dans chacune des sources utilisées, il relève les occurrences de l'expression "religion civile», en présente le contexte d'utilisation, puis compare la signification qui lui est attribuée par son locuteur avec la définition donnée par Rousseau.

2 Dans l'introduction, l'auteur s'attache à rappeler l'ambivalence du terme "religion ", laquelle établit un double lien : transcendantal avec Dieu et social entre les hommes. Il 
souligne ensuite la pérennité des liens établis entre politique et religion depuis l'Antiquité jusqu'au XvIII ${ }^{\mathrm{e}}$ siècle. Il insiste sur la filiation entre Rousseau, Hobbes, Spinoza et Machiavel, qui, le premier, a utilisé la religion dans un dessein politique et social. La pensée de Rousseau apparaît profondément originale en son temps, mais se révèle très souvent déformée ou mal comprise. Malheureusement, l'auteur ne définit pas clairement la "religion civile", au sens où l'entend Rousseau. A la lecture des chapitres suivants, le lecteur attentif peut toutefois comprendre la « religion civile » de Rousseau en ces termes : mise en place par le souverain afin de sacraliser la patrie et les lois, elle présente l'image d'un Être suprême bon, rémunérateur de la vertu, providentiel et juste ; elle repose sur des dogmes dits positifs comme la reconnaissance de l'existence d'une divinité, l'immortalité de l'âme, et un dogme négatif, la liberté des cultes.

3 Michaël Culoma structure son travail en trois volets chronologiques. La période 1762-1789 est traitée dans un chapitre liminaire. Jusqu'en 1789, ce sont surtout des auteurs chrétiens qui utilisent l'expression "religion civile», afin de prendre le contrepied de la théorie antisociale du christianisme développée par Rousseau, mais l'emploi qu'ils en font montre qu'ils n'en saisissent pas complètement les implications, soit qu'ils restent campés sur leurs positions, soit qu'ils ne maîtrisent pas les outils intellectuels appropriés. À partir de 1789, l'expression de "religion civile» fait une lente percée dans le débat politique. L'auteur distingue alors deux étapes : 1789-1792 d'une part, 1793-1794 d'autre part. Avec la Déclaration des droits de l'homme et du citoyen placée sous les auspices de l'Être suprême et dont l'article 10 garantit la liberté religieuse, l'Assemblée constituante pose les bases potentielles pour l'élaboration d'une théorie de la religion civile. A sa tribune, les députés emploient parfois le concept, mais de manière simpliste, le plus souvent pour faire l'apologie de la soumission à la loi, expression de la volonté générale. L'auteur analyse ensuite minutieusement les apparentes similitudes qui ont pu aboutir à une confusion entre la Constitution civile du clergé et la religion civile, les principaux défauts de la première étant, finalement, de toujours renvoyer au catholicisme et de ne pas avoir de contenu dogmatique. Durant la Législative, la théorie de la religion civile est mobilisée lors du débat sur les mesures à prendre à l'encontre des prêtres réfractaires "perturbateurs »: elle est alors assimilée à une mesure de police, destinée à faciliter la réunion de tous les Français. La première construction philosophico-politique du concept s'effectue dans le contexte de mise en place de la République, tandis que la Convention, en exaltant les vertus patriotiques, essaie de consolider l'attachement du citoyen à sa nation. Elle intervient plus particulièrement au moment de la rédaction de la Constitution de 1793. D'après l'auteur, trois conventionnels auraient particulièrement mobilisé la notion de « religion civile » dans leurs discours : Durand de Maillane, Wandelaincourt et Thorillon. Si les divergences et les convergences avec Rousseau sont clairement exposées, on ignore tout de l'insertion du concept dans la pensée théologico-politique de ces députés, ce qui est pour le moins surprenant pour Durand de Maillane, l'un des principaux rédacteurs de la Constitution civile du clergé, ou pour Wandelaincourt, évêque constitutionnel de la Haute-Marne. A partir de septembre 1793, la vague déchristianisatrice ouvre la voie à une conceptualisation plus poussée de la religion civile. Le «culte» de la Raison entre certes en résonnance avec la théorie de Rousseau mais dérive rapidement vers un culte purement rationaliste, ce qui constitue par ailleurs une affirmation très discutable. Avec le vote du décret du 18 floréal an II (7 mai 1794), la théorie de la religion civile atteint son "apogée idéologique». La religion civile des révolutionnaires emprunte 
véritablement l'aspect institutionnel de la religion civile de Rousseau, car elle reconnaît la liberté religieuse, et se fonde explicitement sur des dogmes irrationnels: «la reconnaissance de l'Être suprême et l'immortalité de l'âme». Toutefois, elle s'en démarque dans la mesure où elle n'érige pas certains caractères de la divinité en dogme. Enfin, l'analyse des adresses reçues par la Convention permet d'élargir l'étude à l'espace extra-parlementaire et de mesurer la popularité du décret auprès des sociétés populaires et surtout leur compréhension de l'idée rousseauiste.

Ce travail a le mérite d'attirer à nouveau notre attention sur la réception des idées de Rousseau dans la seconde moitié du xvIII ${ }^{\mathrm{e}}$ siècle, particulièrement dans le débat politique des années 1789-1794. Il démontre que l'emploi révolutionnaire du concept rousseauiste de « religion civile » ne se limite pas aux débats du printemps 1794, mais qu'il apparaît dès le début de la Révolution. Michaël Culoma ne s'attarde pas sur l'examen du concept de « religion civile » chez Robespierre, soulignant lui-même que plusieurs travaux ont déjà été menés sur le sujet. La question de la filiation de Robespierre à Rousseau reste d'ailleurs toujours débattue, comme l'atteste une thèse récente affirmant que la pensée religieuse de l'Incorruptible s'enracinerait autant, sinon plus, dans la pensée de Leibniz que dans celle de Rousseau (cf. J.-M. McDonald, L'Immortalité de l'âme dans la conception religieuse de Maximilien Robespierre : l'influence des idées leibniziennes sur le culte de l'Etre suprême de 1794, Strasbourg, Université Marc Bloch, 2007). L'intérêt de l'étude de Michaël Culoma est surtout d'esquisser des analyses novatrices du concept chez des acteurs politiques moins connus, tels que LecointePuyraveau et Thorillon. Malheureusement, les nombreuses lacunes bibliographiques empêchent toute mise en perspective fructueuse. L'auteur méconnaît ainsi totalement les travaux menés depuis une vingtaine d'années en histoire religieuse de la Révolution, sans parler des grands classiques comme le Théologie et politique au siècle des Lumières de Bernard Plongeron. L'analyse de la conception de la "religion civile» chez les parlementaires de la Révolution, à la seule aune de la pensée de Rousseau, s'avère insuffisante pour comprendre son insertion dans leur système de pensée politique. La notion de "religion civile» employée par chacun des acteurs peut être le résultat d'influences diverses, philosophiques, théologiques, ou même purement circonstancielles. Cet ouvrage constitue donc un bon recueil de citations et de références sur le sujet, mais l'analyse qui en est proposée n'éclaire finalement guère la compréhension des débats religieux dans les assemblées révolutionnaires. 